\title{
The role of Ethics and Targets in Environmental Governance and the enduring importance of the New Public Management
}

\section{Abstract}

This paper examines the importance of the new public management (NPM) in environmental governance. In order to explain what makes NPM such a robust framework for environmental governance, the paper draws on the key themes of individual and collective responsibility in responding to climate change, examining the role of NPM in response to ecological and environmental change, resource scarcity, the focus on global energy sources, and politics. The paper discusses the role of three aspects of environmental governance in turn: the theoretical understandings relating to individuals and society in response to climate change; the politics of these responses and governance arrangements; and how these are formed by the hastening paucity of certain energy resources. The paper then moves on to examine these themes in the context of NPM, arguing that the responses we see to climate change in environmental governance are driven by measurement and targets, as these can be universally set and communicated. This shows the enduring nature of NPM in political and policy responses to the challenges of climate change.

Michael Bradshaw (2014) Global Energy Dilemmas. Cambridge: Polity Press

Tom Christensen and Per Lægreid (eds) (2011) The Ashgate Research Companion to New Public Management. Surrey: Ashgate

Elizabeth Cripps (2013) Climate Change and the Moral World: Individual Duties in an Interdependent World. Oxford: Oxford University Press

Carl Death (ed.) (2014) Critical Environmental Politics. Abingdon: Routledge 
This paper examines the enduring role of the new public management (NPM) and particularly the role of targets and efficiency in environmental governance, and the ethics surrounding the focus and implementation of targets at national and global levels to combat climate change. Why should NPM, evident in a wide range of governance settings since the 1980s, continue to play such a central role in environmental governance? And how should it play this role - particularly given criticisms of the NPM as being too focused on the private sector and too obsessed with outcomes and efficiencies? The paper argues that, despite the complexity of national governments' own aims, supranational regulation, the varieties of NPM, the emergence of network governance, and the expectations of campaign groups, the NPM remains the most suited framework to manage expectations and to mediate targets, efficiencies and outcomes.

The paper begins by discussing the theoretical lenses of the individual, the collective and climate change, examining debates around the moral responsibility which individuals face in determining their own obligations in response to climate change. In examining these debates, the paper focuses on four recent books, which draw together the themes of NPM and environmental governance and policy. Climate Change and the Moral World: Individual Duties in an Interdependent World by Elizabeth Cripps (2013) informs the paper's focus on morality. Global Energy Dilemmas by Michael Bradshaw (2014) and Critical Environmental Politics edited by Carl Death (2014) both focus on the global nature of environmental issues. The final book, The Ashgate Research Companion to New Public Management (2011) edited by Christensen and Per Lægreid, examines the role of NPM in these policy issues and responses to climate change and environmental governance more broadly.

Focusing on the role of new public management in environmental politics and governance, there are several policy examples, such as the Kyoto, Johannesburg and Rio Summits, which highlight the need for a framework to manage governance tensions between countries and the role of supranational organisations. Equally, there is a need to address the concerns of campaign groups and non-governmental organisations (NGOs) in pushing for more ambitious targets, for example, on achieving curbs on emissions and higher levels of recycling, or global agreement and greater spending on these goals.

The discussion in this paper refers to governance, which is distinct from government. Although national governments play a vital part, such as negotiating and signing up to global climate change agreements which dictate targets, there are often wider sets of actors 
involved in climate change policymaking through networks or collaborations involving global governance bodies, NGOs, and the local level in implementing policies.

The paper proceeds as follows. Firstly, the paper focuses on the enduring role of NPM in policy design and mitigation of climate change, both nationally and globally, and argues that the key aspects of NPM remain the dominant force in policy design and responses to climate change. As will be examined in detail, the features of NPM such as efficiency, outcomes, measurement and targets remain key elements of policy for combatting climate change, from the individual, societal, national and global levels. The paper then moves on to discuss the moral and theoretical debates on environmental justice, including the role of the individual and the shared responsibility for combatting climate change, and examines the role of human society, inter- and intra-generational justice, and flora and fauna. Next the paper examines the role of nation states and politics in achieving sustainable responses to climate change, before then embedding these respective debates within the NPM context. The final sections conclude with a discussion of the role of NPM across the moral, energy and political spheres.

\section{The enduring 'nature' of new public management: targets as second nature}

Taking each of the debates set out so far in turn - that is, the moral, global energy and environmental politics - it is evident that each of these presents vast and complex issues which need to be managed both by nation states (with different and competing priorities) and collectively at the global level. In achieving such compromise, we see performance management (emphasised through global-level agreements such as Kyoto, Johannesburg and Rio, and in more everyday policy settings through commitments to reduce carbon emissions), involving measurement and targets. Similarly, the NPM focus on efficiency incentivises governments to think about the short term when making policy.

This can lead to populist policy making which favours immediate economic problems or fossil-fuel driven industries over investment in alternatives such as solar energy, which may be costly in the short term and difficult to sell to voters and the media at times of financial pressure. NPM also has the potential to generate perverse outcomes through measurement of longer-term goals. Governments focused on short-term gain and popularity may sign up to longer-term goals that they will never have to be accountable for implementing. This may also institutionalise notions of moral hazard, through measuring aspects of behaviour like recycling rather than changing long-term behaviours. 
Responses to global catastrophe, often ecological or environmental, have demonstrated (in local, national and global examples) a focus on networks and partnerships, multiagency responses or new public governance. However, implicit in each of these governance arrangements as a response to climate change is the focus on targets. Why is this important?

Conceptually, the enduring nature of new public management is evident in these processes. From a governance perspective there is certainly a focus on targets and outcomes, but also on efficient management processes and delivery. The enduring nature of new public management is not only evident in the reluctance to abandon goals of efficiency and effectiveness; it persists in the idea of targets as the first solution to which we turn in the fight against climate change, which is one of the most problematic conflicts of our era and for future eras. There are three aspects to this reticence of the new public management, its stubbornness

Firstly, the notion of measurement. Whether locally, nationally or globally, government responses to climate change questions are driven by the need to demonstrate improvement. This may be, some might suggest, for instrumental party political and electoral ends as well as in order to save the planet, but that is a question for another debate. The importance of measurement, and the ease of communicating measurement, continues to be the value of NPM. Measurement, in the context of policy responses to climate change, enables communication across problems, sectors and borders; should they wish, it enables governments to pressurise businesses to adopt measures towards carbon reduction, or lower emissions, or higher levels of recycling. Why these specific examples in the context of so many which relate to climate change? Because they can be measured and adopted - or enforced - across organisations which do not have borders, such as transnational corporations. The second enduring value of NPM lies in the related use of efficiency. Taking each of these aspects of NPM in turn, they possess value and suitability in underpinning responses to climate change as a policy problem.

Next targets and measurement. Across different varieties of NPM and in regard to climate change response, the role of delivery is couched through targets. As discussed elsewhere in this paper, there are complex philosophical and individual moral choices to be made in confronting climate change. However, the measurement focus of NPM also has the potential to generate a large amount of data. These transaction costs may prove complex 
and unwieldy, and therefore difficult to translate into realisable policy goals (Painter, 2011: 240).

How can we inform climate change policy design without the knowledge of prior success or failure or general comparison? How can we agree global policy measures to combat climate change without common objectives? Allied to this is the role of the three E's within NPM (efficiency, economy and effectiveness). The notion of efficiency is crucial to combatting the march of climate change, because until funding or broader sustainable and renewable sources are employed more widely, there remains a reliance on scarce fossil fuels, which demands efficiency and clear measurement. However, while the debate at the national and global level focuses on issues such as fracking, hydropower, solar energy and nuclear power, the need for efficiency in regard to the remaining scarce resources and committing funds for research continues to drive policy.

As will be seen throughout this paper, the focus of climate change policy emphasises the role of targets. States agree to policies for achieving future targets as a means of providing demonstrable progress towards goals as well as comparison across time and countries. Targets play a key role in responses to climate change and hence demonstrate the enduring role of NPM. Indeed, targets are often the focus of NGOs and environmental campaign groups as well. The role of targets is an enduring one. Targets are replicable and comparable, and there is no sign of a reduction in the focus on targets and efficiency, reinforcing the endurance of NPM.

Although we have seen a shift in theory towards new public governance and away from the new public management, in practice we still see enduring elements of NPM. Similarly, although we see an overriding emphasis on partnerships and networks, we also see a combination of NPM and new public governance. However, while we can recognise several key elements of NPM in environmental governance, such as the role of targets, measurement and performance, the differences in regard to implementing NPM are equally important. Across different nations and traditions there are several variations of NPM. For example, there are distinctions between the Anglo-Saxon, Southern European and Asian NPM forms of implementation:

'Policy makers and senior bureaucrats choose elements and strategies for administrative reform because they regard them as being in accordance with what has worked well for the administrative system in question in the past, or because they 
regard them as being acceptable in the environment at the present time' (Christensen et al, 2007, cited in Christensen and Laegreid, 2011)

These differences across countries mean that only certain aspects of NPM can be transported to the global level and global policy problems such as a response to climate change. While global policy responses tend to reflect asymmetries in power and roles between nations, environmental policy and NPM, the differences in national and cultural implementations of NPM mean that only certain aspects, rather than the concept as a whole, are utilised at the global level. These elements focus on performance measurement and targets through reductions in carbon and emissions, and increases in recycling. Therefore, the discussion and tension in policy responses tends to be focused on which specific targets to set rather than debating the use of targets at all. This not only demonstrates the endurance of some aspects of NPM but also, as noted above, reinforces the differences in power between nation states in global dilemmas. The Anglo-Saxon NPM model, adopted by the UK and the US, emphasises the approach to measurement:

[T] he Anglophone systems were highly committed to performance management [....] they refined their measurement and performance framework and increased their capacity to monitor performance (Halligan, 2011: 93).

While these variations in NPM are evident in both national and global governance settings, an additional aspect is how they are often joined to partnership arrangements (such as multiagency delivery) as part of climate change mitigation policies, thus involving a range of partners. However, in each of these variations, i.e. the Anglo-Saxon model, the Scandinavian model and the Asian model, there can be seen the common themes of performance management, targets and league tables, as well as key aspects of NPM such as user responsiveness and efficiency (Andrews, 2011).

Through the process of globalisation, from post-socialist states in Eastern Europe to East Asian countries, NPM has become the dominant framework as development increases and public organisations are organised in a more managerialist fashion. However, NPM also lies at the heart of global responses to climate change and environmental governance more broadly, especially given the focus of the key elements discussed here - specifically the role of measurement and targets in designing policies which nation sates and supranational organisations can commit to, combatting environmental degradation, and, at the very least, reducing the speed of climate change. 
The importance of emphasising key aspects of NPM within environmental policy and governance is again evident in the complex map of actors - states, supranational bodies and NGOs - which is further complicated by the role of disaggregation through NPM at the national level (Hansen, 2011), and further still by the use of collaborative partnerships and networks, and notions of public governance (Osborne, 2011). Through NPM, it is these measures, which enable global collaboration and place NPM at the heart of policy responses to climate change. These issues, however, also confront individuals in moral and practical terms, as well as states.

\section{A shared responsibility: Understanding Environmental Governance through theory}

In her book Climate Change and the Moral World: Individual Duties in an Interdependent World (2013) Elizabeth Cripps sets out a number of key debates in responses to climate change which remain unresolved, and examines the theoretical dilemmas and motivations that result from climate change. These relate to the moral role of the individual, in relation to the way one consumes, campaigns and co-exists with other people through inter- and intragenerational justice, and with the Earth's flora and fauna. Cripps draws upon theoretical questions around the role of the individual and social justice.

One of the key tensions and on-going debates around how we govern environmental crisis as a society (across national and global boundaries) is where does responsibility lie in addressing these issues? For example, do we look to global governance mechanisms or national administrations? Do we need to improve regulatory devices and the interaction between governments and corporates? Or, more fundamentally, do we need first to return to the idea of personal responsibility? The underlying principles of this debate lie in the notion of blame rather than responsibility. No one person, certainly in the present time, can be blamed for climate change, emissions or pollution.

This does not, however, lead to the conclusion that we should simply shrug our shoulders, and nor does it suggest that because we are not solely to blame, we should not help. Climate change, although still being challenged as a concept and a reality by some, is increasingly a dramatic reality; this gives us cause to pause and revisit our ideas of self and responsibility. In Climate Change and the Moral World, Cripps sets out a highly innovative, almost 
Hobbesian scenario, where we are confronted by the choice of self or collective responsibility.

\section{Aligning morality and management in environmental policy and developing countries}

That climate change promises to bring about the physical and environmental aspects of a state of nature is even more of an apposite analogy. In challenging us to accept a share of responsibility for solutions and responses to climate change, Cripps frames the key issues in a highly relevant way. The theoretical lens she applies to climate change is more relevant and focused than the didactic use of targets and goals set out by national and global leaders. The essential debates around the role of the individual and the relationship each has with the rest of society represent the key obstacles and debates in responding to and combatting climate change. This theoretical debate about our responsibility to ourselves, to our wider local and global communities, and to future generations, is central to how we use resources and generate emissions in regard to energy, water and fossil fuels.

As Cripps (2013) suggests, individual disagreement on the role of inter- and intragenerational justice creates a major philosophical (and practical) barrier to behaviour change in order to combat climate change. Hence, in terms of governance design and delivery, the focus has remained one of measuring progress. However, in terms of the NorthSouth debate, questions of inter- and intra-generational justice represent an aspect of climate change, which arguably has not yet been sufficiently addressed and brings into the debates the philosophical and moral concerns which Cripps sets out.

Governance responses to this question are driven by mediation and collectivities as much as selves. Northern states aim to curb emissions and pollutants, while Southern states argue that since the Northern nations were able to industrialise at will, it is a question of equity that the Southern states should be able to replicate this philosophy today, even as we are equipped with the knowledge and science around climate change to explore alternatives.

What does this mean for governance? Firstly, and most importantly, it explains the reliance of global governance mechanisms on measurement and targets, which are vital for forecasting, policy design and comparison across time and territories. These (somewhat unresolved) global and moral questions also reinforce the need for governance rather than government. Responses to climate change by national governments should be moral 
responses, to be sure, but they should also ensure the protection of flora and fauna. As individual agents, we must consider the moral duty to non-humans. As Cripps (2013) sets out, to be moral, we should not be speciesist or anthropocentric in our response to climate change. Our individual and collective moral duty extends to animals and plants.

Aligning morality and management in environmental policy and developing countries is an almost impossible task, and one that chimes right back to Brundtland and the discussion of North-South development. In terms of the moral discussion set out above, we are no closer to resolving the tension of allowing developing economies the same scale of development that we witnessed in the Northern hemisphere during the industrial revolution, while simultaneously working with developing countries to collaborate on global environmental policy agreements. Again, within this tension, there is a problem with marrying morality (on both sides of the debate) to the management of environmental governance. This again leads us to the role of targets: the North-South issue is similarly one, which is driven by the negotiation of targets. The role of NPM is present in the focus on achieving targets and outcomes, and also - evidently- in the efficiency of using resources.

\section{A shared responsibility: Understanding Environmental Governance through Politics}

The contributions to Global Environmental Politics (2014), edited by Carl Death, examine a very wide and comprehensive set of debates. These range from an examination of social movements to discussions of ideological approaches to environmental politics such as ecofeminism, discourse and governance. The book also examines wide ranging but related areas with highly complex themes such as intergenerational justice and the North-South divide. Some sustainability scholars, from a variety of disciplines, tell us these debates are out of date. However, in terms of practical reality and governance we are not a great deal nearer to finding a truly global solution, which all actors can agree on.

This is a central point as it emphasises the role of governance rather than government in this process, not just from a global but also a national and local perspective. Moreover, the diverse range of interests examined in this book and invested in environmental politics underlines the importance of NPM. How can policymakers mediate and unite diverse groups within their policy response? Taken together, aspects such as resource violence, sustainability and limits all require elements of measurement, efficiency and targets. In terms 
of resource violence, therefore, this means to measure and manage sustainably existing fuels and to limit their use (Death, 2014).

\section{Global issues, local problems, different progress: the role of targets and outcomes}

Global Energy Dilemmas by Michael Bradshaw (2014) focuses on how different nation states respond to crises in energy and resources. Bradshaw investigates a number of nation states experiencing energy dilemmas in different ways. These nation states are at different stages of development and thus have different moral constraints and policy options open to them in approaching energy usage. Bradshaw divides these states into different categories of high-energy states, post-socialist states, developing countries and emerging economies.

These differing perspectives demonstrate the difficulty in achieving a global response to energy scarcity and usage and reflect the broader moral issues examined by Cripps, such as moral constraint. For example, is it possible for high-energy nations to expect developing countries to consume less while simultaneously stressing the need to allow them to develop independently from aid? This problem again brings into focus the role of key aspects of NPM: targets, measurement, efficiency and performance. To be sure, NPM is itself open to such variations, but the global nature of energy and broader environmental policy responses requires that policy be reconciled around these core aspects. Hence there has tended to be a focus on achieving targets to measure and improve policy performance in response to climate change and for its mitigation.

In the same vein, how do we connect as individuals with the ecological and environmental catastrophe in different geographical areas? One way in which this happens is through energy and the role of diminishing resources. This brings into sharp focus the global-local debate and the question of inter- and intra-generational justice. Both of these issues raise the question of energy and resource use, both by individuals and by society as a collective. Locally, nationally and globally, the use of such scarce and diminishing resources needs to be tracked. On such a global scale, how better to perform this task than by measurement, in order to compare progress or otherwise in combatting climate change? And how better to achieve this than by policies which link the local and global? However, although there has been consistent consensus on this at the supranational level (within the EU, for example), in terms of the role of individual states this has been a more complex issue. Aside from the reticence of the US over Kyoto in 1997, we have also seen an on-going debate between China and the West over emissions. As Bradshaw (2014) notes, different issues are 
prioritised by powerful or poorer nations. Similarly, nations develop at different rates and experience political change at different times, and this has implications for energy use. For example, 'energy dilemmas' (Bradshaw, 2014) differ between post-socialist states and the West and also between these states and emerging and developing nations and economies.

The need to mediate between these differing stages of energy use (and development) again brings the focus onto the role of targets and measurement. In each of these energy use contexts, Bradshaw highlights the role of targets and efficiency. For example, measurement is applied to the size of population, the amount of energy used, the quantity of coal burned, and the reduction predicted:

In 1800, the world's population was roughly 1 billion people and total global energy use was approximately 20 exajoules (EJs). By 1900, world energy use had increased to 50 EJs and the population to 1.6 billion people; by the end of the twentieth century, energy use had raced to $430 \mathrm{EJ}$ and the population to 6.1 billion. Thus, in 200 years, the population increased sixfold and energy use twentyfold (Bradshaw, 2014: 5).

The role of targets and efficiency is clearly drawn upon in the statistics above, highlighting the pressure and overuse of resources through rapid industrial expansion and development. Measuring historical resource use during industrialisation has reinforced the need for NPM in documenting empirically the progress of energy use and population growth as factors in environmental degradation. The need to measure progress in combatting climate change through industrialisation as well as issues such as inter-generational justice and the NorthSouth divide demand cooperation across future climate change strategy, and also a measurement of the effectiveness of this. Equally fundamentally, the role of globalisation, the formation of political-economic blocs and the transition to markets has underpinned the need for a collaborative response to climate change and to managing energy use. Because of increased supply chains, trade and expanding populations, energy use has increased exponentially. However, the policy response to this development has been one firmly couched in managerialism, necessitating the use of NPM. As Bradshaw notes:

'[Policy response] suggests that a transition to a market economy, where prices reflect the true cost of production and delivery and the energy system is largely in private hands, will impose discipline upon energy producers and consumers, thus promoting greater efficiency' (Bradshaw, 2014: 98). 
This approach was reinforced through supranational governance, for example within the EU, and had the resultant effect of compliance to such standards by accession (or would-be) accession countries such as the transitioning post-socialist states in Eastern Europe. Coupled to the Anglo-Saxon model of NPM and the surge in production in East Asia, the dominant efficiency paradigm required a governance framework to complement it. As we have seen, the different strands of NPM all share an emphasis on efficiency and performance.

\section{Governing Climate Change: The fight for resources and the relationship between governance, the individual and nature}

Of course, governance responses to climate change cannot simply be thought of as the responsibility of corporations, nation states, global governance actors and campaigners. The various strands of the debate involve issues such as biodiversity, resource violence and anthropocentrism. Each of these requires a political responses and the linkage between these areas is again one of moral reason, focused on the relationship between the individual and their natural and social environment in observing environmental justice by consuming and replacing resources sustainably. Each of these areas has its own politics, and each demands of us moral and ethical consideration in terms of our individual role and place in nature, as well as in society.

Again, in terms of responses, how do we unite such a range of issues? Each one comprises both local and global factors, and as such they need effective governance mechanisms. How can we demonstrate improvement in these highly normative areas, and how do we chart progress over time and compare it? There is a relationship between ethics and targets here: in considering campaigns and NGOs, it is often the targets, which are challenged, rather than the concept of targets itself.

However, in using scarce resources, we have an individual responsibility to prevent resource violence (Watts and Peluso, 2014). Drawing upon scarce resources requires monitoring and measurement. The need to link and understand consumption alongside citizenship, and to see these acts as part of a broader biopolitics in combatting climate change, requires a shift in behaviour to be undertaken by the individual, as discussed above, as well as effectiveness 
within new social movements. It is to be hoped that the local-global focus of sustainability will enable individual behaviour change.

\section{Concluding Remarks}

This paper has examined the role of targets in environmental governance, and questioned how ethical it is to continue to use NPM as a framework in the response of government to climate change. The paper has argued that although there is a need to revisit our individual and societal responses to climate change, the use of NPM mechanisms such as measurement, efficiency and targets is essential for demonstrating change or progress in areas such as recycling, reductions in emissions levels, or carbon reduction. NPM measurement allows comparison between different nations and over time.

As has been shown, the role of targets in environmental governance is of an enduring nature and something which has been applied across such diverse areas of the debate as protest groups, new social movements, corporations and governments at both the national and global governance level. The tenacity of targets and efficiency is underpinned by the need for protest movements and NGOs to campaign for more ambitious targets and spending, such as calling for reductions in carbon emissions or putting pressure on other nation states to conform to global agreements to mitigate climate change.

As we have seen, the scope of environmental governance is extremely broad, covering areas such as eco feminism, sustainability, governance itself, security, resources, and the role of the individual in relation to the collective physical and natural environment. The underlying tension in striving for a more moral relationship in governing our environment is one which has echoes of NPM within it; for example, there is a focus on the individual in terms of self-reliance, responsibility and morality. There is also a focus on targets and outcomes, as we have seen. This apparent linkage, however, merely demonstrates the strength and tenacity of the key elements of NPM. The focus on targets and outcomes is, to be sure, a central element of large aspects of national and international environmental policy. However, the reach of these is even more telling in shaping and driving the responses to policy from NGOs and protest groups. These responses also often have recourse to the key tenets of NPM: they do not dispute the use and focus on targets per se, but rather, they question which targets are chosen, in terms of efficiency and outcomes. Unsurprisingly, the 
role of resources is also a key factor in environmental governance. The pressing need to enact reforms and to draw upon solar or nuclear energy rather than our vastly depleted fossil fuels reinforces the need for targets, efficiency and measurement.

\section{References}

Andrews, R. (2011) 'NPM and the Search for Efficiency’ in: Christensen, T. and Lægreid, P. (eds) The Ashgate Research Companion to New Public Management. Surrey: Ashgate, pp. 281-294.

Bradshaw, M. (2014) Global Energy Dilemmas. Cambridge: Polity Press

Christensen, T. and Lægreid, P. (eds) (2011) The Ashgate Research Companion to New Public Management. Surrey: Ashgate

Cripps, E. (2013) Climate Change and the Moral World: Individual Duties in an Interdependent World. Oxford: Oxford University Press

Death, C. (ed.) (2014) Critical Environmental Politics. Abingdon: Routledge

Halligan, J. (2011) 'NPM in Anglo-Saxon Countries’ in: Christensen, T. and Lægreid, P. (eds) The Ashgate Research Companion to New Public Management. Surrey: Ashgate, pp. 8396.

Hansen, H. (2011) 'NPM in Scandinavia' in: Christensen, T. and Lægreid, P. (eds) The Ashgate Research Companion to New Public Management. Surrey: Ashgate, pp. 113-130.

Osborne, S. (2011) 'Public Governance and Public Services: A 'Brave New World' or New Wine in Old Bottles?' in: Christensen, T. and Lægreid, P. (eds) The Ashgate Research Companion to New Public Management. Surrey: Ashgate, pp. 417-430.

Painter, M. (2011) 'Managerialism and Models of Management' in: Christensen, T. and Lægreid, P. (eds) The Ashgate Research Companion to New Public Management. Surrey: 
Ashgate, pp. 237-250.

Watts, M. and Peluso, N. (2014) 'Resource Violence' in: Death, C. (ed.) Critical Environmental Politics. Abingdon: Routledge, pp. 184-197. 